ఠ

ORIGINAL RESEARCH

\title{
miR-I34 increases the antitumor effects of cytarabine by targeting Mnks in acute myeloid leukemia cells
}

This article was published in the following Dove Press journal: OncoTargets and Therapy

\author{
Kankan Chen \\ Yue Chen \\ Zhi Chen \\ Yuye Shi \\ Zhengmei He \\ Banghe Ding \\ Chunling Wang \\ Liang Yu
}

Department of Hematology, the Affiliated Huaian No I People's Hospital of Nanjing Medical

University, Huaian, Jiangsu, China
Correspondence: Liang Yu Department of Hematology, the Affiliated Huaian No I People's Hospital of Nanjing Medical University, 6 West Beijing Road,

Huaian, Jiangsu, China

Tel/fax +865I78492 2412

Email yuliang19772।3@|26.com

\begin{abstract}
The relapse and resistance to cytarabine (Ara-C) therapy is still a dominating obstacle to the successful clinical treatment of acute myeloid leukemia (AML). Recent studies have shown that dysregulation of miRNAs might modulate the resistance of cancer cells to anticancer drugs; yet, the mechanism is not fully understood. In this study, we showed a significant downregulation of miR-134 in human multidrug-resistant leukemia cells and relapsed/refractory AML patient samples. Overexpression of miR-134 sensitized K562/A02 and HL-60/ADM cells to Ara-C, inhibited cell colony formation, and enhanced the ability of Ara-C to induce apoptosis. Mechanistic analyses revealed that Mnks was a putative target of miR-134, which was inversely correlated with miR-134 expression in human multidrug-resistant leukemia cells and relapsed/ refractory AML patient samples. Further investigation showed that miR-134 increased the antitumor effects of Ara-C through inhibiting phosphorylation of eukaryotic initiation factor $4 \mathrm{E}$ and downregulating Mcl-1 and bcl2, which was independent of p38 and Erk1/2 activation. Taken together, our results demonstrate that miR-134 plays a pivotal role in AML Ara-C resistance through increasing cell sensitivity to Ara-C and promoting apoptosis by targeting Mnks.
\end{abstract}

Keywords: miR-134, acute myeloid leukemia, Mnks, eIF4E, apoptosis

\section{Introduction}

Acute myeloid leukemia (AML) is a genetically heterogeneous clonal disorder leading to proliferation and accumulation of leukemic blasts in blood, marrow, and other organs. ${ }^{1}$ Despite significant remission rates of chemotherapy, about $70 \%$ of AML patients will relapse and are associated with resistance and toxicity, resulting in dismal long-term survival rates and poor quality of life..$^{2,3}$ The need for novel therapeutic approaches is urgent and of high clinical importance.

Multiple signaling pathways that promote leukemic cell survival and proliferation are constitutively activated in AML cells, providing potential therapeutic targets. Among them, the Ras/Raf/MAPK and the PI3K/Akt/mTOR signaling pathways are two vital cascades involved in the poor prognosis of AML and its development of resistance to cytarabine (Ara-C) treatment. ${ }^{4-7}$ Activation of these pathways has been associated with most AML cases. The oncogenic activity of the eukaryotic initiation factor $4 \mathrm{E}$ (eIF4E) driven by the Mnk kinases is a node of convergence of the two cascades. ${ }^{8,9}$

Mnks belong to a serine/threonine kinases family and two Mnk human genes, Mnk1 and Mnk2, have been identified. eIF4E is phosphorylated usually at Ser209 by Mnk kinases in response to mitogens and stress signals, and it subsequently promotes the synthesis of tumorigenic proteins..${ }^{9} 10$ eIF4E is essential for cap-dependent 
mRNA translation and represents a key regulator in the control of mRNA translation and protein expression. ${ }^{11,12}$ Even moderate overexpression of eIF4E could cause dysregulated proliferation and tumorigenic transformation in immortalized cell lines including AML. ${ }^{12,13}$ Induction of antiapoptotic proteins was believed to play an important role for the relapse and resistance to Ara-C therapy. Those studies support a critical role for Mnk/eIF4E axis in the development of AML and indicate that targeting the Mnk/eIF4E axis may be a promising therapeutic strategy for the treatment of AML. However, efforts have been limited by the lack of Mnk inhibitor compounds with the potential for clinical development.

miRNAs are a class of short, noncoding RNA molecules with a significant regulatory capacity on gene expression and play an important role in various physiologic and pathologic processes, such as apoptosis, cell proliferation and differentiation. ${ }^{14}$ miR-134 has recently been shown to be downregulated in a variety of diseases including cancers. For example, Sun et al found that miR-134 suppresses non-small cell lung cancer development through downregulation of oncogenic CCND1. ${ }^{15}$ In addition, miR-134 is frequently downregulated in renal cell carcinoma cells and inhibits cell proliferation and epithelial-to-mesenchymal transition by targeting KRAS. ${ }^{16}$ However, the role of miR-134 in AML has not been reported to the best of our knowledge. The aim of this study is to explore the biologic functions of miR-134 in AML and the underlying mechanisms. Here, we reported that miR-134 is downregulated in relapsed/refractory AML patient samples and human leukemia AML multidrug-resistant cell lines, and found that miR-134 sensitized K562/A02 and HL-60/ADM cells to Ara-C and promoted cell apoptosis by targeting the 3' untranslated region (3'UTR) of Mnks.

\section{Materials and methods}

\section{Patients and bone marrow samples}

Forty-one newly diagnosed AML patients, 25 relapsed/ refractory AML patients, and 27 healthy controls were included in this study. Diagnosis of AML was established according to clinical presentation and morphologic criteria of the French-American-British Classification. Leukemic mononuclear cells were isolated from the bone marrow by density-gradient centrifugation. Among these AML patients, six matched-pair bone marrow samples were available both at the diagnosis time prior to treatment and the relapsed/ refractory state. An informed written consent in compliance with the Helsinki declaration was obtained from all the patients. The study was approved by the Ethics Committee of Huai'an First People's Hospital.

\section{Cell culture and transfection}

The human leukemia cell lines, K562 and HL-60, and their multidrug-resistant counterparts, K562/A02 and HL-60/ $\mathrm{ADM}$, were purchased from the Department of Pharmacology, the Institute of Hematology of Chinese Academy of Medical Sciences (Tianjin, China). The cells were maintained in DMEM at $37^{\circ} \mathrm{C} / 5 \% \mathrm{CO}_{2}$. The cells were cultured for 2 weeks in drug-free medium prior to their use in the experiments. miRNA mimics for miR-134, as well as the negative control, were chemically synthesized from GE Dharmacon. Transfections were performed with Lipofectamine 2000 Reagent (Thermo Fisher Scientific, Waltham, MA, USA) following the manufacturer's instructions.

\section{RNA isolation and quantitative real-time polymerase chain reaction ( $q R T-P C R$ )}

Total RNA was extracted from cell lines and tissues using the Trizol reagent (Thermo Fisher Scientific). To detect miR-134 expression, cDNA was reverse transcribed using TaqMan miRNA RT Kit (Life Technologies) and U6 was used as endogenous control. To detect Mnks expression, cDNA was reverse transcribed using a high-capacity cDNA reverse transcription kit (Thermo Fisher Scientific) and GAPDH was used as endogenous control. The qRT-PCR assays were analyzed by the Step One Plus RT-PCR system (Thermo Fisher Scientific) using SYBR PrimeScript RT-PCR Kit (Takara Bio, Shiga, Japan).

\section{CCK-8 assay}

After $24 \mathrm{~h}$ transfection, $5 \times 10^{3}$ K562/A02 and HL-60/ADM cells were seeded into $96-w e l l$ plates. Ara-C was prepared freshly at various concentrations and then added. After $48 \mathrm{~h}$ incubation, cell viability was assessed by CCK-8 assay. Absorbance value at $490 \mathrm{~nm}$ was then measured. The concentration at which each drug produced $50 \%$ inhibition of growth $\left(\mathrm{IC}_{50}\right)$ was estimated by the relative survival curve. At least three independent experiments were performed in quadruplicate.

\section{Colony formation assay}

Cells were seeded for the colony forming assay on six-well culture plates at 200 cells per well, in triplicate. After 14 days of incubation at $37^{\circ} \mathrm{C}$ with $5 \% \mathrm{CO}_{2}$, colonies were fixed with acetic acid-methanol (1:4) and stained with dilute crystal violet (1:30) prior to being manually counted. Colonies containing 50 cells or more were counted as survivors.

\section{Luciferase reporter assay}

A fragment of the wild or mutated 3'UTR of Mnk1/2 that contained the putative miR-134 binding sites was cloned into 
downstream of the luciferase gene in the pGL3-REPORT luciferase vector (Thermo Fisher Scientific) at the HindIII and SpelI sites. For the luciferase assay, 293T cells were seeded in 24-well plates $24 \mathrm{~h}$ before transfection. The cells were co-transfected with pGL3-3'UTR and the control reporter plasmid, and miR-134 mimics or miRNA negative control. After $48 \mathrm{~h}$, the luciferase activity was measured with a dual luciferase reporter assay system (Promega, Madison, WI, USA). Luciferase activity was normalized to Renilla luciferase activity for each transfected well.

\section{Cell apoptosis analysis}

K562/A02 and HL-60/ADM were plated in six-well plates $\left(6 \times 10^{5}\right.$ cells/well). After $24 \mathrm{~h}$ transfection, K562/A02 and HL-60/ADM cells were treated with Ara-C at a final concentration of $5 \mu \mathrm{M}$. After $48 \mathrm{~h}$ of treatment with Ara-C, the cells were stained with Annexin $\mathrm{V}$ and propidium iodide (BD Biosciences, San Jose, CA, USA) and then analyzed through flow cytometry (BD FACSAria ${ }^{\mathrm{TM}}$ Fusion).

\section{Western blot}

Antibodies directed against bcl2, Mcl-1 (Mcl-1L), Mnk1, Mnk2, eIF4E, and phosphorylated eIF4E at Ser209 (p-eIF4E), obtained from Abcam, were used to determine protein level by Western blot. $\beta$-actin (Abcam) was used as a loading control.

\section{Statistical analysis}

All data from three independent experiments were expressed as mean $\pm \mathrm{SD}$. Statistical analysis was performed using the GraphPad Prism Software. Statistical comparisons were performed using Student's $t$-test, and $p$-values $<0.05$ were considered significant.

\section{Results}

\section{Downregulation of miR-I 34 expression in bone marrow blasts from relapsed/ refractory patients and human leukemia AML multidrug-resistant cell lines}

To investigate whether miRNA participated in drug resistance in AML, the expression of miR-134 was first assessed in bone marrow blasts from AML patients using qRT-PCR. Results revealed that miR-134 expression was significantly $(p<0.05)$ reduced in relapsed/refractory patients in comparison to newly diagnosed AML patients (Figure 1A). However, no difference in miR-134 was observed between newly diagnosed AML patients and healthy controls. In six
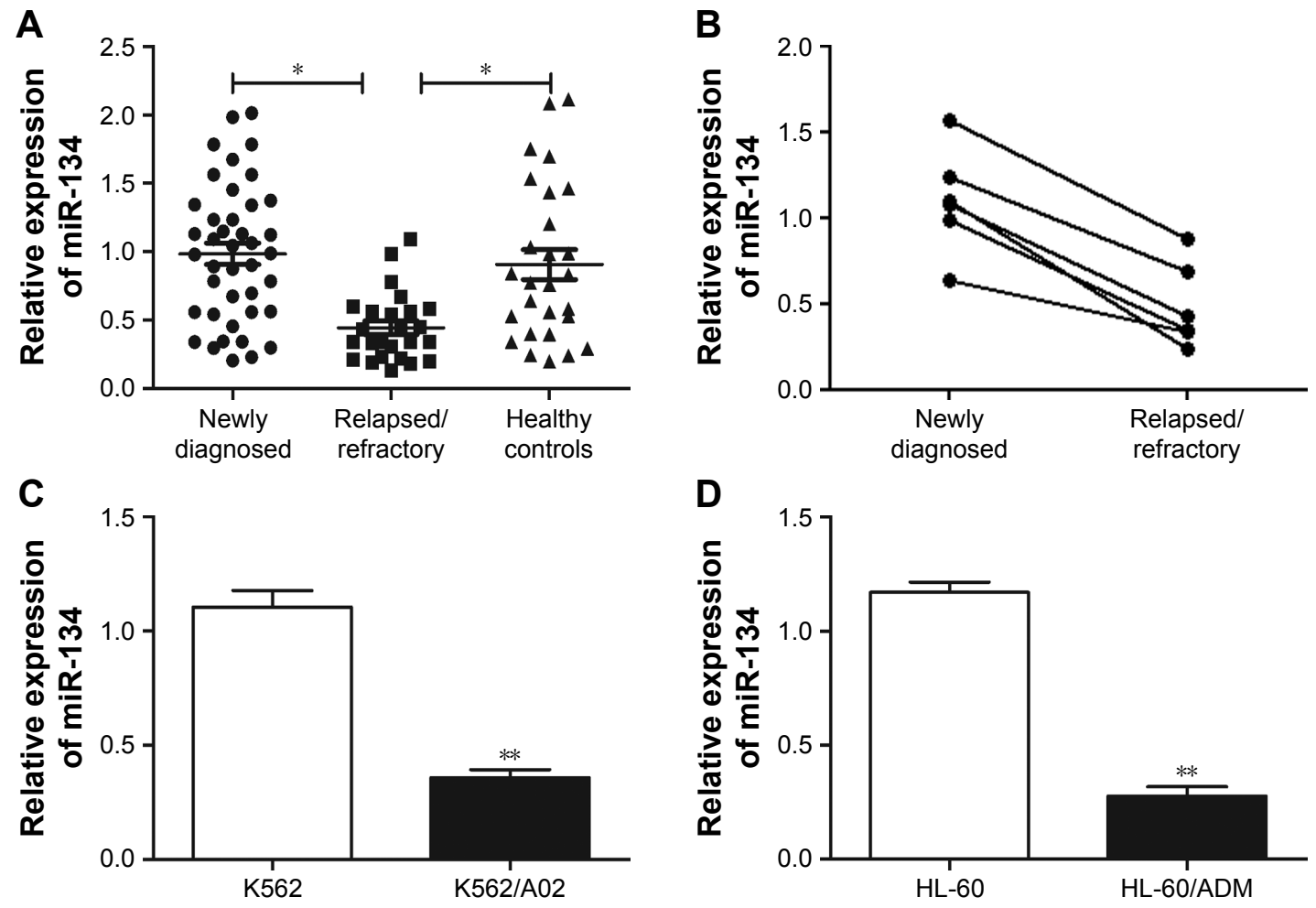

Figure I qRT-PCR analysis of miR-134 expression in relapsed/refractory AML patients and human leukemia AML multidrug-resistant cell lines.

Notes: (A) Relative expression of miR-134 in 4 I newly diagnosed AML patients, 25 relapsed/refractory AML patients, and 27 healthy controls. (B) Relative expression of miR-134 in six matched-pair bone marrow samples of AML patients at the diagnosis time prior to treatment and the relapsed/refractory state. (C) Relative expression of miR-I34 in K562 cells and multidrug-resistant K562/A02 cells. (D) Relative expression of miR-I34 in HL-60 cells and multidrug-resistant HL-60/ADM. *p<0.05, **p<0.0I. Abbreviations: AML, acute myeloid leukemia; qRT-PCR, quantitative real-time PCR. 
patients, matched-pair bone marrow samples were available both at diagnosis time prior to treatment and the relapsed/ refractory state. We found a high level of miR-134 at diagnosis, whereas an obvious decrease of miR-134 expression was observed in the relapsed/refractory state (Figure 1B). Next, we examined miR-134 expression in human leukemia AML multidrug-resistant cell lines, and results demonstrated a lower expression of miR-134 in K562/A02 and HL-60/ADM cell lines, in comparison to that of their matched controls (K562 and HL-60), as shown in Figure 1C and D.

\section{miR-I 34 enhances Ara-C sensitivity and induces apoptosis in K562/A02 and HL-60/ADM cells}

To further confirm the correlation between miR-134 and Ara-C drug resistance in AML, K562/A02 and HL-60/ADM cells were transiently transfected with miR-134 mimics or negative control. qRT-PCR assays demonstrated that miR-134

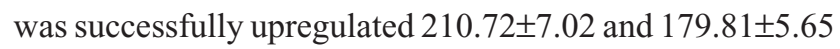
fold in K562/A02 and HL-60/ADM cells transfected with miR-134 mimics, respectively ( $p<0.01$; Figure $2 \mathrm{~A}$ ). In both K562/A02 and HL-60/ADM cells, CCK-8 assay verified that those transfected with miR-134 mimics exhibited greatly enhanced sensitivity to Ara-C compared with the miRNA mimics control-transfected cells, respectively (Figure 2B). Colony formation assay also showed that overexpression of miR-134 inhibited the K562/A02 and HL-60/ADM cell colony formation (Figure 2C). To test whether miR-134 could mediate cell apoptosis in regulation of Ara- $\mathrm{C}$ resistance, we analyzed Ara-C-induced apoptosis after transfection of K562/A02 and HL-60/ADM cells with the miR-134 mimics by flow cytometry. In both K562/A02 and HL-60/ADM cells,
A

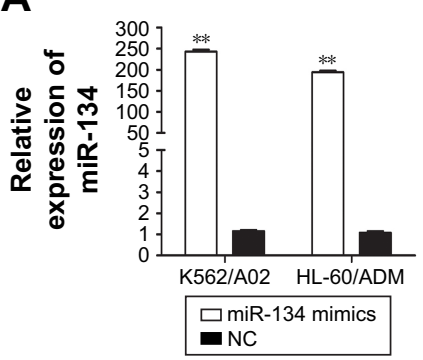

C

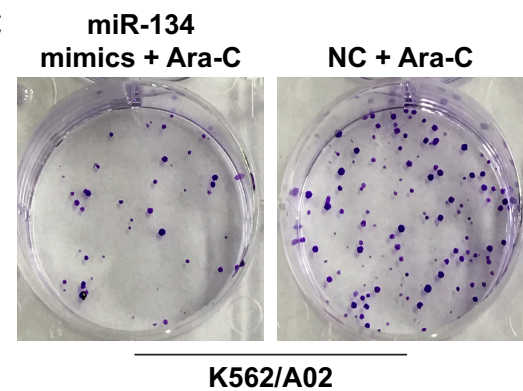

D

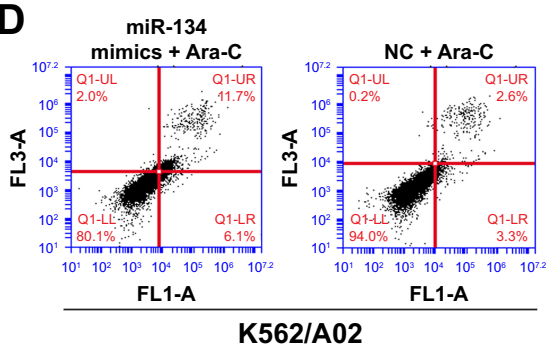

B

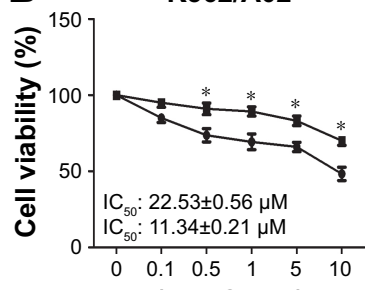

(Ara-C: $\mu \mathrm{M}$ )

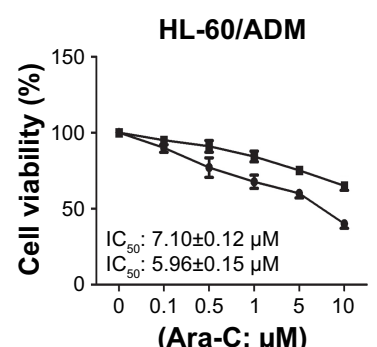

(Ara-C: $\mu \mathrm{M}$ )

\section{$\rightarrow$ miR-134 mimics $\rightarrow \mathrm{NC}$}

miR-134
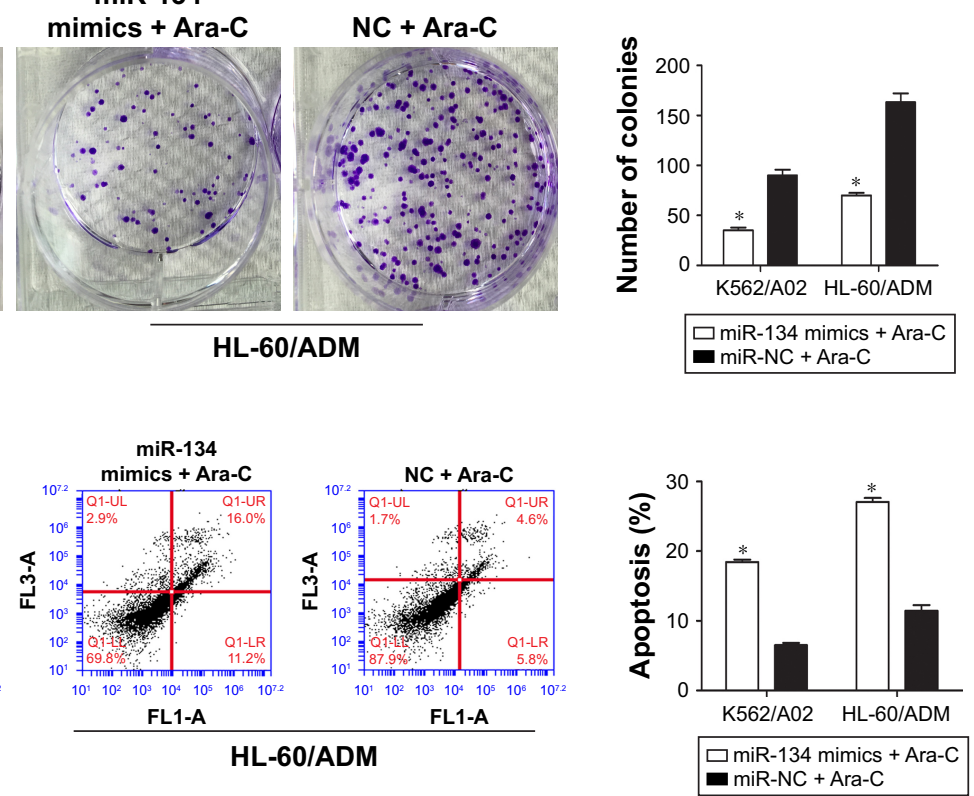

Figure 2 Overexpression of miR-134 enhances Ara-C sensitivity and induces apoptosis in K562/A02 and HL-60/ADM cells.

Notes: (A) Relative expression of miR-134 in K562/A02 and HL-60/ADM cells transfected with miR-I34 mimics and negative control. (B) Effect of miR-I34 on cell proliferation in K562/A02 and HL-60/ADM cells transfected with miR-I34 mimics and negative control. (C) Representative images of colony formation assay of K562/A02 and HL-60/ADM cells transfected with miR-134 mimics and negative control and treated with Ara-C. (D) Effect of miR-134 on cell apoptosis in K562/A02 and HL-60/ADM cells transfected with miR-I34 mimics and negative control and treated with Ara-C. $* p<0.05, * * p<0.01$.

Abbreviations: Ara-C, cytarabine; $\mathrm{IC}_{50}$, half maximal inhibitory concentration; NC, normal control. 
overexpression of miR-134 resulted in a notable increase in cell apoptosis after Ara-C treatment compared with the negative control, respectively (Figure 2D).

\section{miR-I34 negatively regulates $\mathrm{Mnk}$ I/2}

To explore the potential molecular mechanism of chemoresistance and apoptosis regulated by miR-134 in AML cells, we searched different databases (TargetScan and microRNA. org) for its potential targets involved in chemoresistance and apoptosis, and results demonstrated that Mnks was a predicted target of miR-134 (Figure 3A). Luciferase reporter assay results showed that miR-134 dramatically inhibited luciferase activity in $293 \mathrm{~T}$ cells when the reporter plasmid carried the wild-type Mnks 3'UTR, but no significant inhibition was observed when the reporter plasmid carried a mutation (Figure 3B). Western blot results demonstrated that an obvious decrease of Mnk1/2 protein level was observed in transfected miR-134 mimics cells compared with the negative control cells in both K562/A02 and HL-60/ ADM cells, respectively (Figure 3C). The expression of Mnks in bone marrow blasts from relapsed/refractory AML patients and human leukemia AML multidrug-resistant cell lines was also determined by qRT-PCR and Western blot (Figure 3D and E).

\section{miR-I 34 inhibits phosphorylation of elF4E and downregulates $\mathrm{Mcl}-\mathrm{I}$ and $\mathrm{bcl} 2$}

To investigate the effect of miR-134 on MAPK-mediated eIF4E pathways, Western blot analysis was performed after transfection with miR-134 mimics or miRNA mimic negative control in K562/A02 and HL-60/ADM cells. As expected, restoration of miR-134 in both K562/A02 and HL-60/ADM cells reduced the levels of respective Mnk1/2 mRNA expression by $\sim 70 \%-85 \%$ (Figure $4 \mathrm{~A}$ and B). Phosphorylation of
A

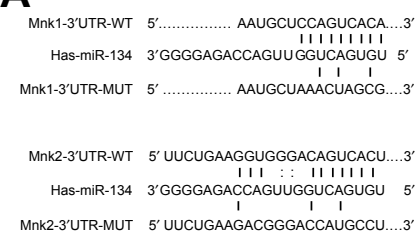

B

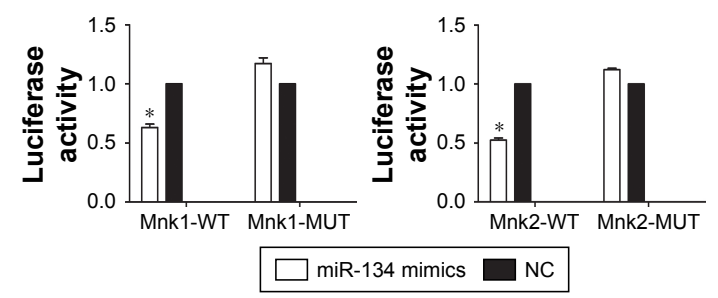

C

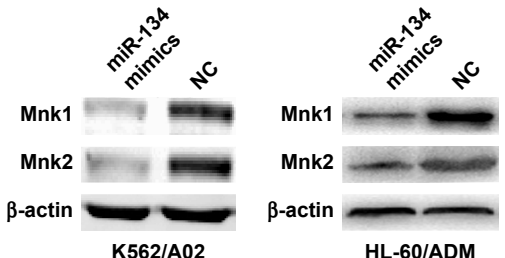

D
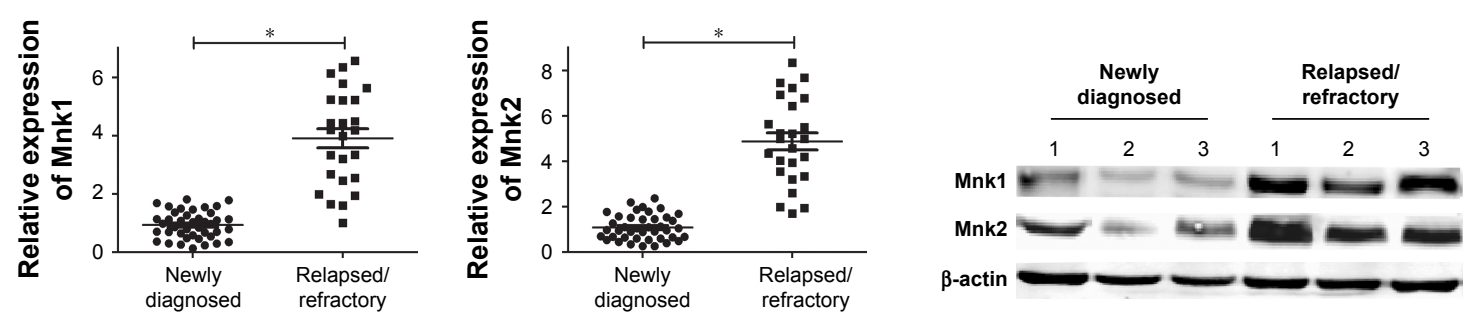

E
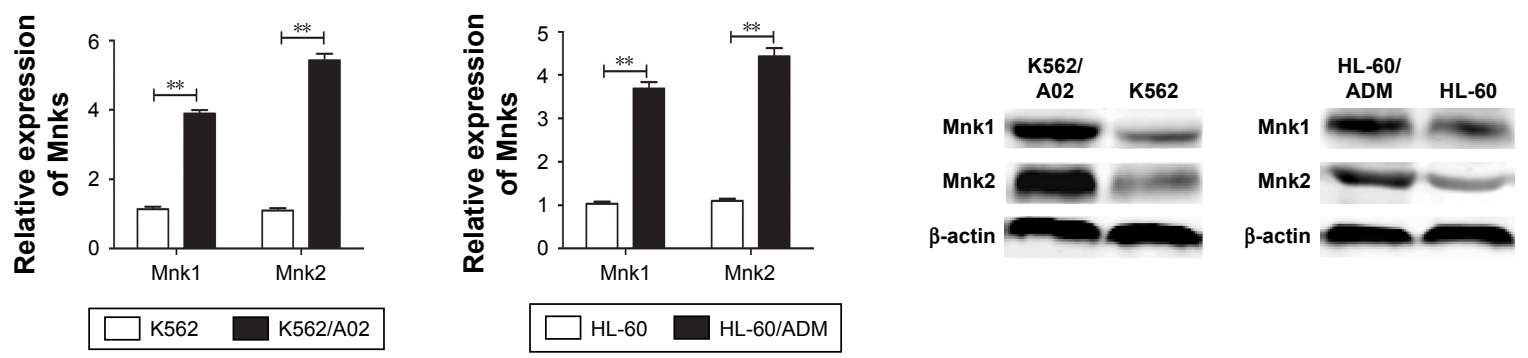

Figure 3 miR-134 negatively regulates Mnkl/2.

Notes: (A) Predicted binding sequences of miR-134 in the 3'UTR of MnkI/2. (B) Relative luciferase activity of 293T cells after co-transfection with WT or MUT Mnks 3'UTR or the control reporter plasmid, and miR-134 mimics or negative control. (C) Quantification of MnkI/2 protein expression in K562/A02 and HL-60/ADM cells. (D) Quantification of Mnkl/2 mRNA expression in $4 \mathrm{I}$ newly diagnosed AML patients, 25 relapsed/refractory AML patients, and protein expression in three matched-pair bone marrow samples of AML patients at the diagnosis time prior to treatment and the relapsed/refractory state. (E) Quantification of Mnk $1 / 2$ mRNA and protein expression in $\mathrm{K} 562 / \mathrm{A} 02$ and $\mathrm{HL}-60 / \mathrm{ADM}$ cells. ${ }^{*} p<0.05$, ${ }^{*} p<0.0$ I.

Abbreviations: 3'UTR, 3' untranslated region; AML, acute myeloid leukemia; elF4E, eukaryotic initiation factor 4E; MUT, mutant type; NC, normal control; WT, wild type. 
A

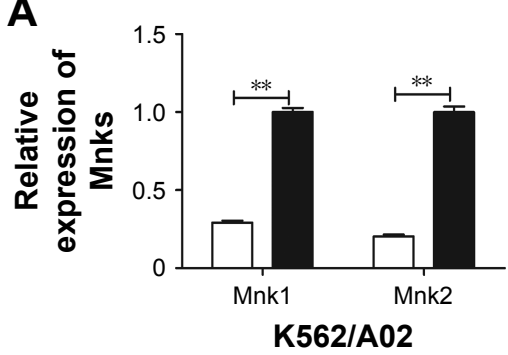

B

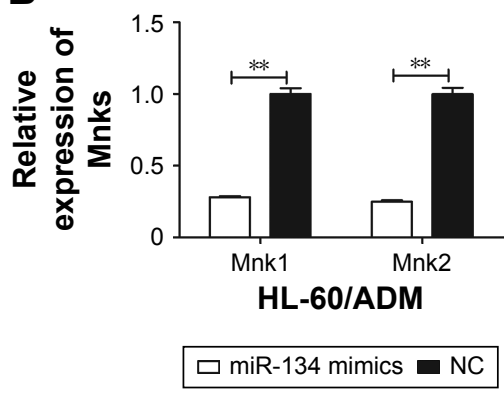

C

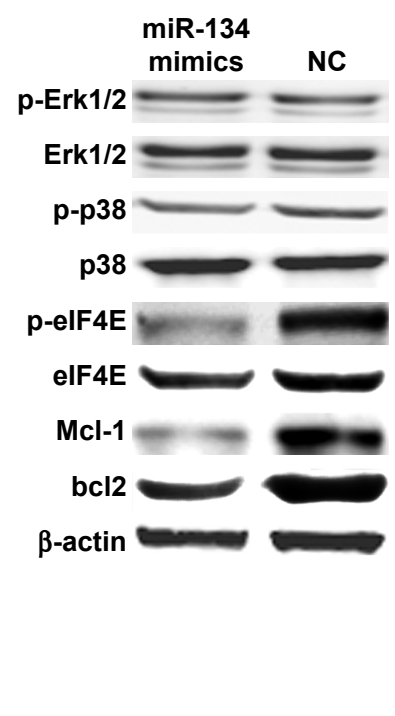

D

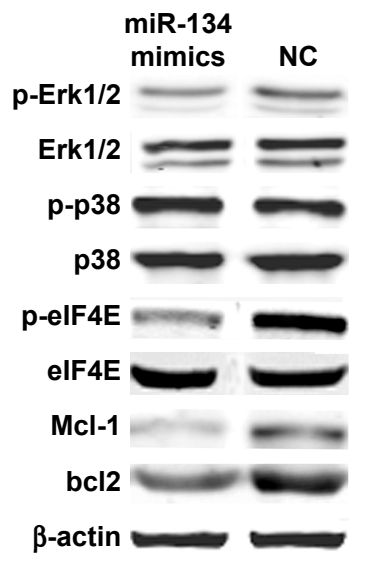

Figure 4 miR-I34 inhibits phosphorylation of elF4E and downregulates Mcl-I and bcl2.

Notes: (A) Quantification of MnkI/2 mRNA expression in K562/A02 cells. (B) Quantification of MnkI/2 mRNA expression in HL-60/ADM cells. (C) Effect of miR-134 on the expression of the phosphorylation of ErkI/2, p38, elF4E, Mcl-I, and bcl2 in K562/A02 cells. (D) Effect of miR-I34 on the expression of the phosphorylation of ErkI/2, P38, elF4E, Mcl-I, and bcl2 in HL-60/ADM cells. ** ${ }^{*}<0.01$.

Abbreviations: elF4E, eukaryotic initiation factor 4E; NC, normal control; p-elF4E, phosphorylation-elF4E; p-Erkl/2, phosphorylation-Erkl/2; p-p38, phosphorylation-p38.

Erk1/2 and p38 was not affected, while phosphorylation of eIF4E, Mcl-1, and bcl2 in miR-134-transfected cells was significantly reduced compared to miRNA mimic negative control transfected cells (Figure 4C and D).

\section{Discussion}

Ara-C has been one of the cornerstone drugs in the treatment of AML for more than three decades. ${ }^{17}$ Both intrinsic and acquired chemotherapeutic resistance develops in patients after prolonged treatment with Ara-C, which is a major limitation in the successful treatment of AML. ${ }^{18}$ Evidence suggests that drug resistance mechanisms are involved in downregulated expression of hENT1, reduced intracellular concentrations of Ara-CTP and the active triphosphorylated form of Ara-C. ${ }^{18-20}$ In this work, we studied the functional role of miR-134 and the mechanism underlying its control of Ara-C-induced resistance in AML.

This study revealed that miR-134 expression was downregulated in bone marrow blasts from relapsed/refractory AML patients and human leukemia AML multidrug-resistant cell lines compared with newly diagnosed AML patients and parallel drug-sensitive cell lines, respectively. Meanwhile, Ara-C is a primary drug for AML treatment in clinical practice. These results indicate that miR-134 might be involved in Ara-C-induced resistance. To check this hypothesis, CCK-8 assay and flow cytometry analysis were employed in K562/A02 and HL-60/ADM cell lines, and we found that miR-134 enhances Ara-C sensitivity and promotes cell apoptosis. This finding compliments previous observations that miR-134 was associated with gefitinib resistance in lung adenocarcinoma cells by targeting MAGI2, paclitaxel resistance in human ovarian cancer cells by regulating Pak2, and cisplatin resistance in triple-negative breast cancer through controlling STAT5B. ${ }^{21-23}$

Recent studies have found that the activated PI3K/Akt/ mTOR and MAPK signaling pathways are involved in Ara-C resistance. ${ }^{24-26} \mathrm{Mnk} / \mathrm{eIF} 4 \mathrm{E}$ axis is a specific and critical regulator of these two pathways. In this study, Mnks was confirmed to be a direct target of miR-134 by Western blot and luciferase reporter assay, and there was a negative correlation between the expression of miR-134 and Mnks in both relapsed/refractory AML patients and AML multidrugresistant cell lines (Figure 3). Further investigations of the effects of miR-134 on Mnk/eIF4E axis showed that miR-134 inhibits phosphorylation of eIF4E and downregulates Mcl-1 and bcl2, independent of $\mathrm{p} 38$ and Erk1/2 (Figure 4). Taken together, these findings suggest that miR-134 sensitizes Ara-C-resistant AML cells and promotes cell apoptosis through targeting Mnk/eIF4E axis, and subsequently reduces Mcl-1 and bcl2 expression.

To summarize, we have shown that miR-134 can promote cell apoptosis and increase sensitivity to Ara-C by targeting 
Mnks. The miR-134-Mnk-eIF4E axis may provide new insights into the mechanisms of AML chemoresistance, and the restoration of miR-134 expression may offer a new strategy for the treatment of AML in the future.

\section{Acknowledgments}

We gratefully thank Dr Yufeng Li from the Department of Hematology, Huai'an First People's Hospital for his helpful suggestions and advice during this project. Grants were provided by the Huai' an Science and Technology Plan (No HAP201423) and the Huai'an New Research Project of Clinical Diagnosis and Treatment (No HAS2014008, HAS2015026 and HAS201608).

\section{Disclosure}

The authors report no conflicts of interest in this work.

\section{References}

1. Estey E, Döhner H. Acute myeloid leukemia. Lancet. 2006;368(9550): 1894-1907.

2. Davila J, Slotkin E, Renaud T. Relapsed and refractory pediatric acute myeloid leukemia: current and emerging treatments. Paediatr Drugs. 2014;16(2):151-168.

3. Estey EH. Treatment of acute myeloid leukemia. Haematologica. 2009;94(1):10-16.

4. Platanias LC. Map kinase signaling pathways and hematologic malignancies. Blood. 2003;101(12):4667-4679.

5. Martelli AM, Evangelisti C, Chiarini F, Grimaldi C, Manzoli L, McCubrey JA. Targeting the PI3K/AKT/mTOR signaling network in acute myelogenous leukemia. Expert Opin Investig Drugs. 2009; 18(9):1333-1349.

6. Nishioka C, Ikezoe T, Yang J, Yokoyama A. Inhibition of MEK signaling enhances the ability of cytarabine to induce growth arrest and apoptosis of acute myelogenous leukemia cells. Apoptosis. 2009; 14(9):1108-1120.

7. Khokhar NZ, Altman JK, Platanias LC. Emerging roles for mammalian target of rapamycin inhibitors in the treatment of solid tumors and hematological malignancies. Curr Opin Oncol. 2011;23(6):578-586.

8. Wang X, Yue P, Chan CB, et al. Inhibition of mammalian target of rapamycin induces phosphatidylinositol 3-kinase-dependent and Mnkmediated eukaryotic translation initiation factor $4 \mathrm{E}$ phosphorylation. Mol Cell Biol. 2007;27(21):7405-7413.

9. Hou J, Lam F, Proud C, Wang S. Targeting Mnks for cancer therapy. Oncotarget. 2012;3(2):118-131.

10. Diab S, Kumarasiri M, Yu M, et al. MAP kinase-interacting kinasesemerging targets against cancer. Chem Biol. 2014;21(4):441-452.
11. Sonenberg N, Gingras AC. The mRNA 5 'cap-binding protein eIF4E and control of cell growth. Curr Opin Cell Biol. 1998;10(2):268-275.

12. Topisirovic I, Guzman ML, McConnell MJ, et al. Aberrant eukaryotic translation initiation factor 4E-dependent mRNA transport impedes hematopoietic differentiation and contributes to leukemogenesis. Mol Cell Biol. 2003;23(24):8992-9002.

13. Altman JK, Szilard A, Konicek BW, et al. Inhibition of Mnk kinase activity by cercosporamide and suppressive effects on acute myeloid leukemia precursors. Blood. 2013;121(18):3675-3681.

14. Bartel DP. MicroRNAs: genomics, biogenesis, mechanism, and function. Cell. 2004;116(2):281-297.

15. Sun CC, Li SJ, Li DJ. Hsa-miR-134 suppresses non-small cell lung cancer (NSCLC) development through down-regulation of CCND1. Oncotarget. 2016;7(24):35960-35978.

16. Liu Y, Zhang M, Qian J, et al. miR-134 functions as a tumor suppressor in cell proliferation and epithelial-to-mesenchymal transition by targeting KRAS in renal cell carcinoma cells. DNA Cell Biol. 2015; 34(6):429-436.

17. Moore AS, Kearns PR, Knapper S, Pearson AD, Zwaan CM. Novel therapies for children with acute myeloid leukemia. Leukemia. 2013; 27(7):1451-1460.

18. Galmarini CM, Thomas X, Calvo F, et al. In vivo mechanisms of resistance to cytarabine in acute myeloid leukemia. $\mathrm{Br} J$ Haematol. 2002;117(4):860-868

19. Kanno S, Hiura T, Ohtake T, et al. Characterization of resistance to cytosine arabinoside (Ara-C) in NALM-6 human B leukemia cells. Clin Chim Acta. 2007;377(1-2):144-149.

20. Sarkar M, Han T, Damaraju V, Carpenter P, Cass CE, Agarwal RP. Cytosine arabinoside affects multiple cellular factors and induces drug resistance in human lymphoid cells. Biochem Pharmacol. 2005;70(3): 426-432.

21. Kitamura K, Seike M, Okano T, et al. MiR-134/487b/655 cluster regulates TGF- $\beta$-induced epithelial-mesenchymal transition and drug resistance to gefitinib by targeting MAGI2 in lung adenocarcinoma cells. Mol Cancer Ther. 2014;13(2):444-453.

22. Shuang T, Wang M, Shi C, Zhou Y, Wang D. Down-regulated expression of miR-134 contributes to paclitaxel resistance in human ovarian cancer cells. FEBS Lett. 2015;589(20 Pt B):3154-3164.

23. O'Brien K, Lowry MC, Corcoran C, et al. miR-134 in extracellular vesicles reduces triple-negative breast cancer aggression and increases drug sensitivity. Oncotarget. 2015;6(32):32774-32789.

24. Martelli AM, Evangelisti C, Chiarini F, McCubrey JA. The phosphatidylinositol 3-kinase/Akt/mTOR signaling network as a therapeutic target in acute myelogenous leukemia patients. Oncotarget. 2010; 1(2):89-103

25. Martelli AM, Tazzari PL, Evangelisti C, et al. Targeting the phosphatidylinositol 3-kinase/Akt/mammalian target of rapamycin module for acute myelogenous leukemia therapy: from bench to bedside. Curr Med Chem. 2007;14(19):2009-2023.

26. Li P, Diab S, Yu M, et al. Inhibition of Mnk enhances apoptotic activity of cytarabine in acute myeloid leukemia cells. Oncotarget. 2016;7(35):56811-56825.
OncoTargets and Therapy

\section{Publish your work in this journal}

OncoTargets and Therapy is an international, peer-reviewed, open access journal focusing on the pathological basis of all cancers, potential targets for therapy and treatment protocols employed to improve the management of cancer patients. The journal also focuses on the impact of management programs and new therapeutic agents and protocols on

\section{Dovepress}

patient perspectives such as quality of life, adherence and satisfaction. The manuscript management system is completely online and includes a very quick and fair peer-review system, which is all easy to use. Visit http://www.dovepress.com/testimonials.php to read real quotes from published authors. 